\title{
Laboratory Study on Sludge Treatment by Electro-Osmosis Combined with Pile-Loading
}

\author{
Xiaoyu Fan ${ }^{1}$, Weiyu Wang ${ }^{1}$, Yaxing $\mathrm{Wei}^{1}$, Kun $\mathrm{Cao}^{1}$ \\ ${ }^{1}$ College of Civil Engineering, Hebei University, Baoding, Hebei 071002, China \\ Email: fanxiaoyu456@126.com
}

\begin{abstract}
In practical engineering, electro-osmotic treatment of large-scale silt projects will cause a lot of electricity waste. Some scholars have made an electro-osmotic method to treat silt and combine pile-loading to reduce the energy consumption of electric energy. In this paper, the effects of electro-osmotic treatment combined with pile-loading experiment on the consolidation of municipal sludge and the content of heavy metals in the sludge before and after electro-osmosis are analyzed and the conclusions are drawn.(1)The combination of electro-osmotic method and pile-loading experiment has strong capacity of drainage consolidation.(2)The contents of copper and zinc decreased obviously, and the electro-osmotic method combined with pile-loading method had a certain effect on the treatment of heavy metals in silt.
\end{abstract}

Keyword: Electro-osmotic method, combined pile-loading, heavy metal, silt

\section{Research Status of Electro-osmosis}

Zang Junchao and others did the experiment of electro-osmosis reinforcement of contaminated soil in February 2017. They studied the characteristics of electro-osmotic reinforcement of contaminated soil from domestic sources, and analyzed the four parameters of water content reduction percentage, energy consumption per unit displacement, shear strength and soil settlement. The sequence of primary and secondary factors influencing the effect of electro-osmotic drainage reinforcement of contaminated soil is obtained: Power supply voltage $>$ electrification time $>$ initial water content $>\mathrm{CaCl} 2$ addition $>$ electrode material[1]. In the study of treatment of heavy metals in sludge of municipal sewage treatment plant by electrodialysis, Chen Wenting[2] used electrodialysis device to carry out electrodialysis experiment on sludge of sewage treatment plant. Samples were taken every 2 hours and then treated with Tessier five-step method. It is found that electro-osmotic method is feasible for heavy metal treatment. Wang Jun and others made use of the independently developed experimental device in 2014 to conduct indoor model tests on the combination of electro-osmotic method and closed vacuum preloading method to strengthen soft clay foundation. It was found that vacuum preloading and electro-osmotic method can promote each other under the combined action. The results show that the compatibility is better than that of vacuum preloading alone in the treatment of soft clay foundation[3]. In 2014, Jiao Dan carried out the electro-osmotic test of soft clay under different initial and electrified conditions in axisymmetric working conditions on a self-made electro-osmotic consolidation device. It was found that under the same water content and voltage, the electric energy utilization ratio of soil was higher when intermittent electricity was switched on. And the overall difference of soil after electro-osmosis is small[4]. In the experimental study of low energy dynamic compaction combined with electro-osmotic method for strengthening soft clay foundation, Fu Hongtao found that the electric energy consumption increases during the process of electro-osmosis, and the problem of electro-osmosis can be effectively remedied after combined dynamic compaction[5]. Ren Jubo has found in the experimental study of the new surcharge electro-osmosis method to reinforce the foundation of dredged silt that the combined action of electro-osmosis and surcharge can effectively reduce the soil moisture content, improve the shear strength of the soil, and make the soil settle and consolidate[6].

A large number of experiments on sludge treatment by electro-osmosis have only been focused on reinforcement effect and electro-osmosis research on the basic physical properties of sludge. Nowadays, if the heavy metal content in the silt can be treated well, the stress of the urban soil can be greatly alleviated. In this paper, the changes of heavy metals in the sludge of urban sludge treated by electro-osmotic method 
combined with loading experiments are described.

\section{$2 \quad$ Research Content Methods and Basic Parameters}

\section{$2.1 \quad$ Research Contents}

In this paper, the measurement and calculation of water content, density, dry density, void ratio, porosity, saturation, shear strength, heavy metal (copper, zinc) content of sludge treated by electro-osmosis combined with pile-loading treatment were carried out. By real-time monitoring of the three-point settlement and recording current of $\mathrm{A}, \mathrm{B}, \mathrm{C}$, the data are summarized at the end of the paper.

\section{$2.2 \quad$ Experimental Scheme}

(1) An organic glass box with a length of $50 * 30 * 40(\mathrm{~cm})$ is used in the experiment, and the bottom of the organic glass box is provided with a small hole with a diameter of $1 \mathrm{~cm}$ at the bottom and is connected with a soft rubber pipe for electro-osmosis drainage, and coarse sand with the bottom layer of $5 \mathrm{~cm}$ is provided with a drainage layer for drainage in the coarse sand.

(2)Sludge is taken from a city's artificial landscape lake.

(3)Application of three bar $(\mathrm{d}=1.5 \mathrm{~cm})$ as electro-osmosis anode, uses three carbon $(\mathrm{d}=1.5 \mathrm{~cm})$ as a cathode electro-osmosis, wrapped in cloth is inserted in the permeable width near each electrode $(2 \mathrm{~cm})$ band drain. Insert three sets of electrodes (two sets of output voltage $30 \mathrm{~V}$, arranged on both sides. The other set of output voltages is $5 \mathrm{~V}$, arranged in the middle.)

(4)Using iron blocks at the top to simulate the load of $20 \mathrm{kPa}$.

(5)The current is measured with a multimeter during electro-osmosis.

(6) The content of heavy metals in soil was measured once in 4 hours.

The layout and equipment diagrams are as follows:
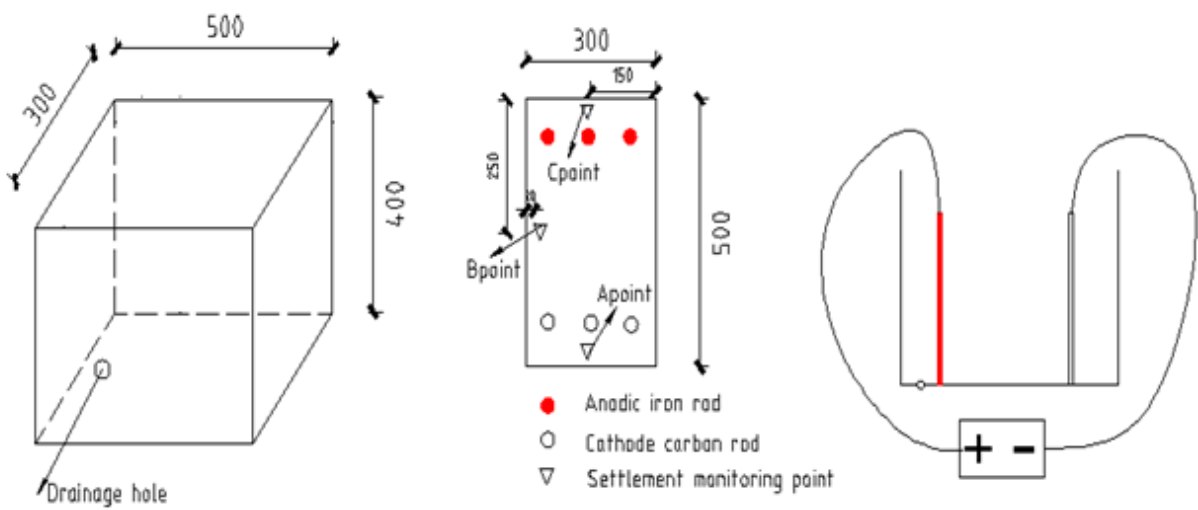

Figure 2-1. Experimental layout 


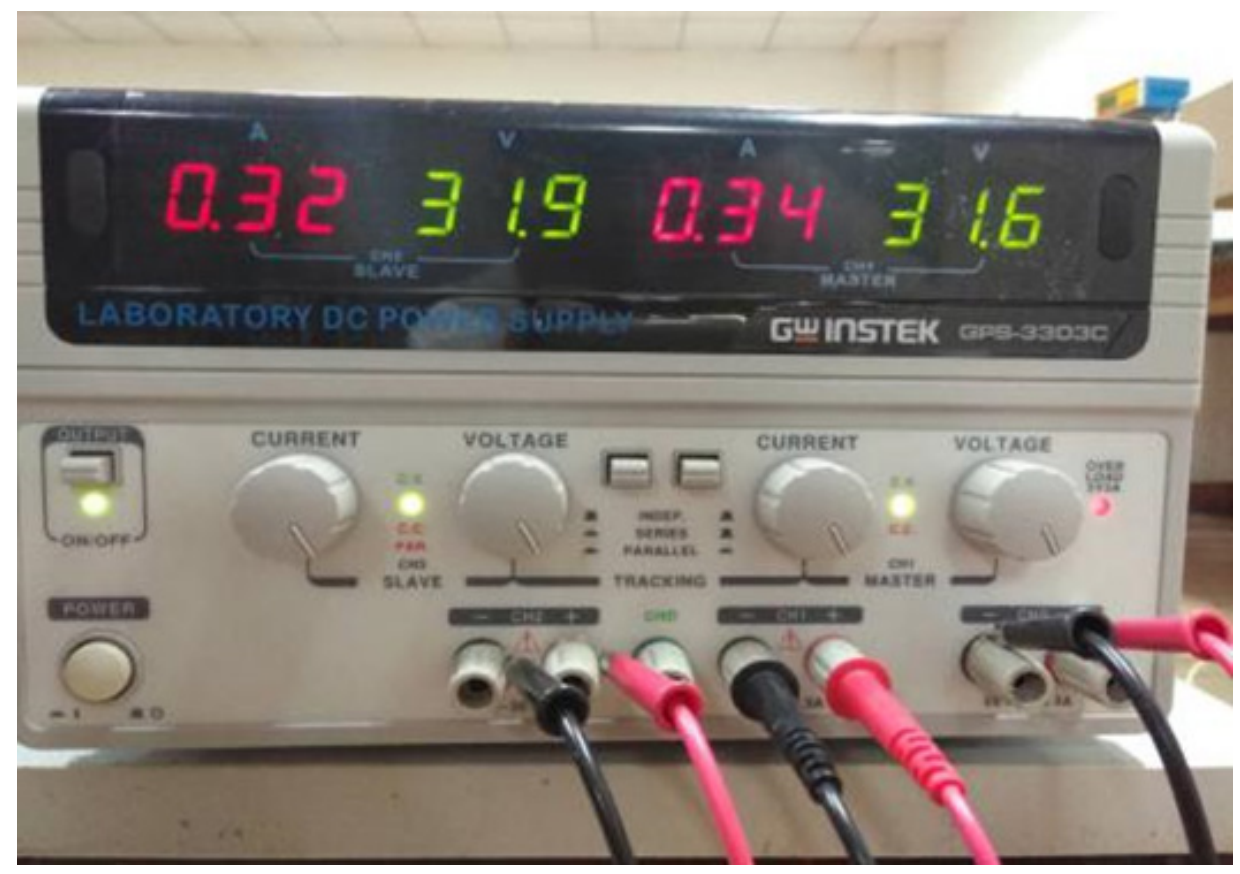

Figure 2-2. Guwei DC power supply

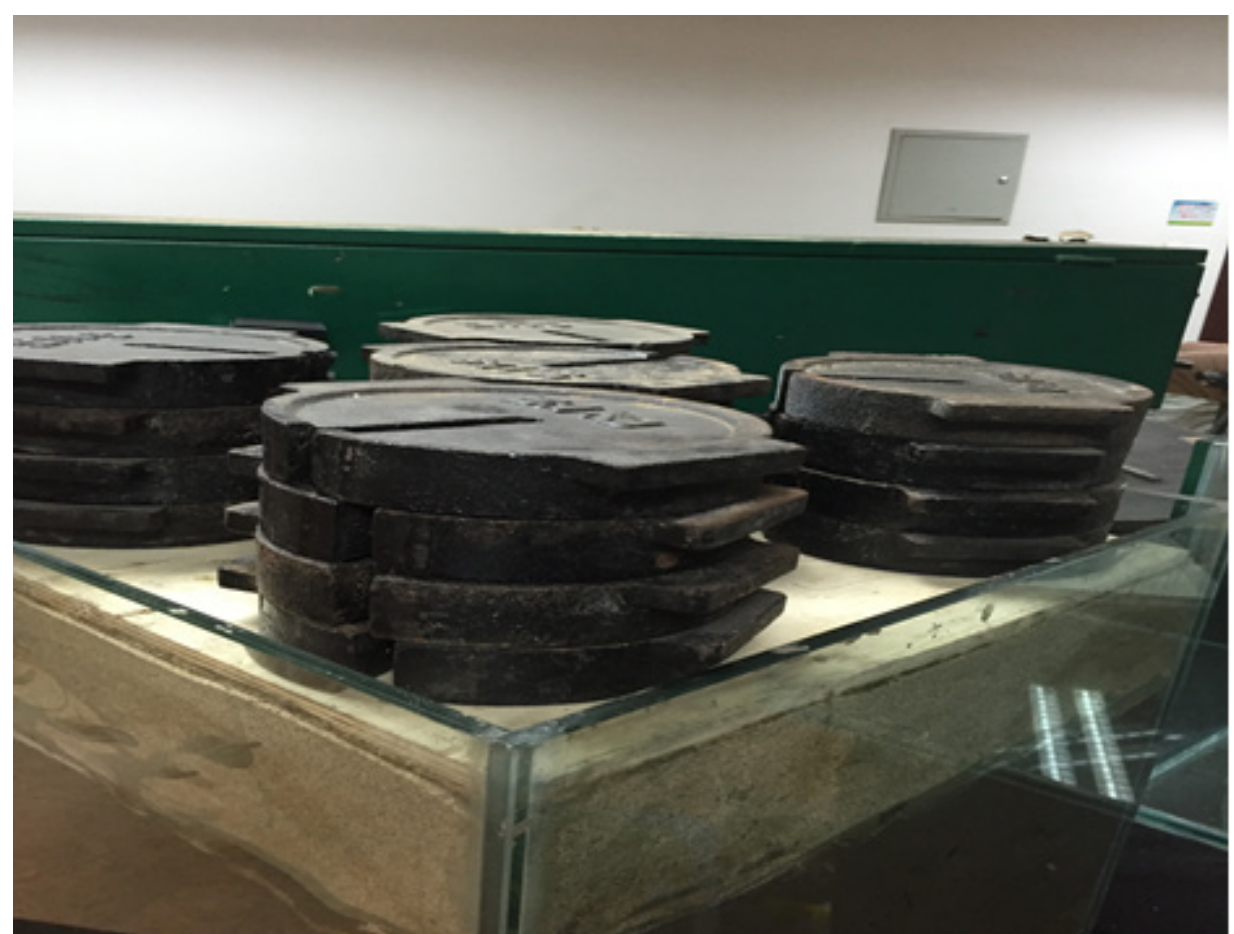

Figure 2-3. Test chart of loading

\subsection{Basic Parameters before Electro-osmosis}

The basic mechanical indexes of soil were measured and calculated according to the standard of soil test method (GB-T50123-1999). The sludge needs to be measured as follows before the experiment. The results are as follows: rate of water content, density, dry density, void ratio, porosity and saturation. 
Table 2-1. Basic parameters of soil before electro-osmosis

\begin{tabular}{lllllll}
\hline $\begin{array}{l}\text { Density } \\
\mathrm{g} / \mathrm{cm}^{3}\end{array}$ & $\begin{array}{c}\text { Dry density } \\
\mathrm{g} / \mathrm{cm}^{3}\end{array}$ & $\begin{array}{l}\text { Specific gravity } \\
\text { of solid Gs }\end{array}$ & $\begin{array}{c}\text { Moisture content } \\
\%\end{array}$ & $\begin{array}{l}\text { Porosity } \\
\text { ratio }\end{array}$ & Porosity & $\begin{array}{c}\text { Saturation } \\
\%\end{array}$ \\
\hline 1.50 & 1.06 & 2.7 & $40.72 \%$ & 1.54 & 0.606 & $71.42 \%$ \\
\hline
\end{tabular}

The plastic limit value of the soil is $\omega_{P}=15.19$ and the liquid limit is $\omega_{L}=33.02$. The permeability coefficient of soil is $1.7068 \times 10-6$ by the method of variable water head penetration test.

\section{$3 \quad$ Experimental Data Analysis}

\section{(1) Analysis of Drainage Rate}

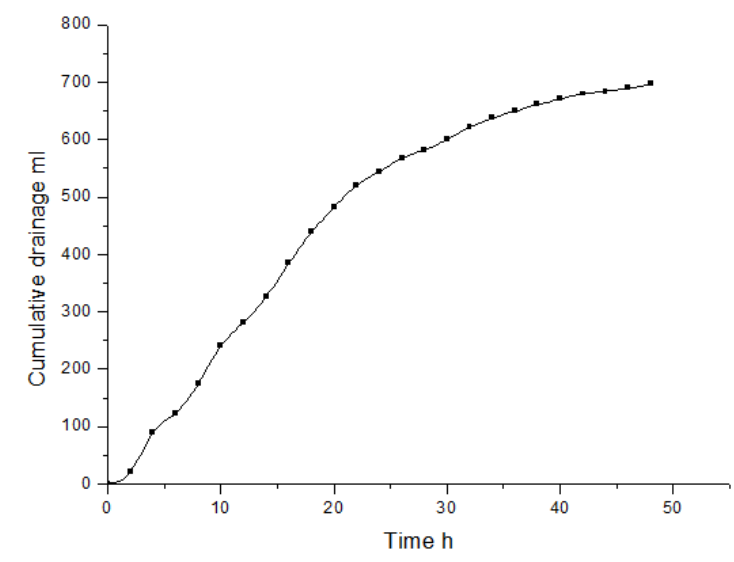

Figure 3-1. Drainage change map

The total amount of drainage in 48 hours is $695.5 \mathrm{ml}$, the average drainage rate reaches the maximum $25 \mathrm{ml} / \mathrm{h}$ in $1 \mathrm{~h} \sim 20 \mathrm{~h}$, and the maximum hourly displacement reaches $65 \mathrm{ml} / \mathrm{h}$. After that, the drainage rate gradually slows down. At the end of electrification, the drainage rate remains at the rate of $3.1 \mathrm{ml} / \mathrm{h}$. It can be seen that the drainage process is not over and has not reached the limit value of electro-osmotic treatment.

(2)Analysis of Current Change

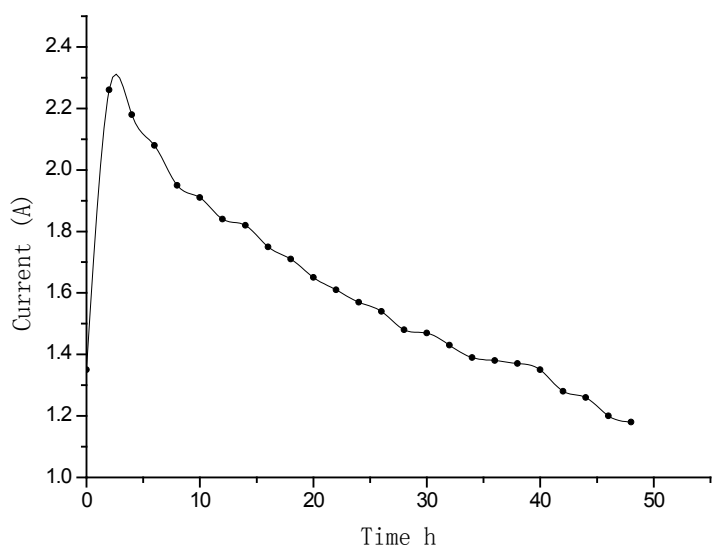

Figure 3-2. Change of current in the process of experiment 


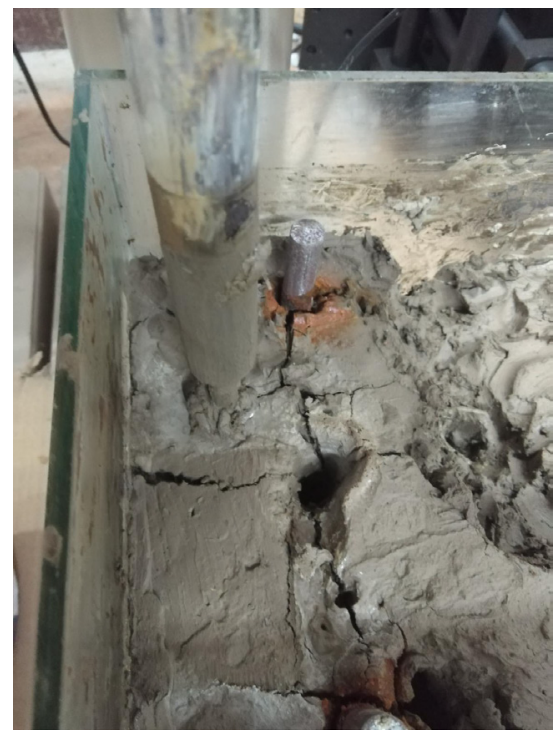

Figure 3-3. Surface cracks

There is no apparent sharp decrease in current in $48 \mathrm{~h}$. It can be seen that there is little chance of large cracks in the soil. However, cracks in the soil surface still occur during the experiment, and the surface cracks appear at the end of the test. A total of two cracks appear in the anode. The width is $1 \sim 3 \mathrm{~mm}$, and the depth is only in the $2 \sim 3 \mathrm{~cm}$ range.

(3) Experimental Settlement Analysis of Electro-osmotic Pile-loading

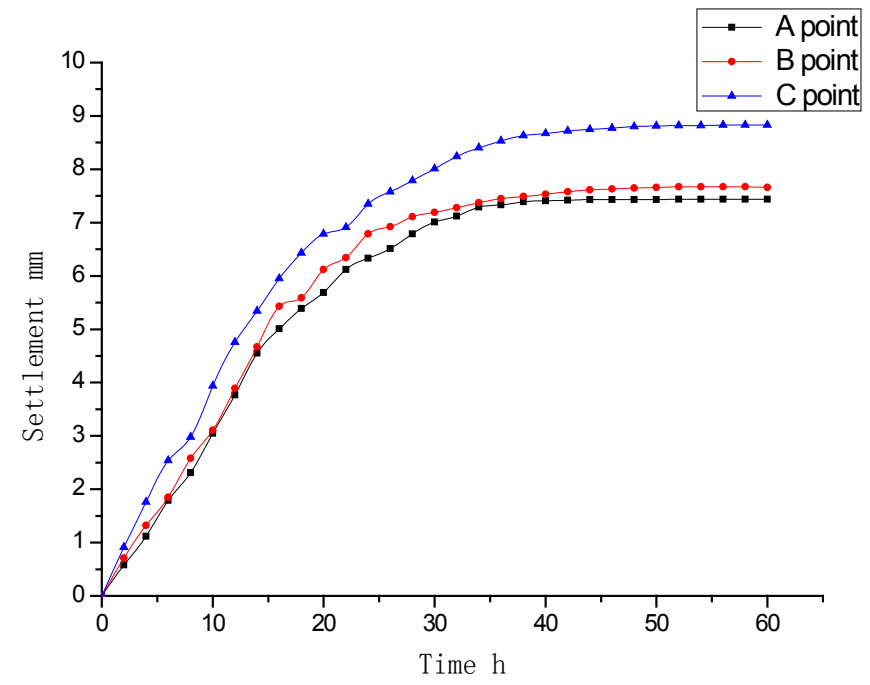

Figure 3-4. The change of soil settlement during the experiment

From the above figure, we can see that the settlement of electro-osmotic process accords with the general law of electro-osmotic infiltration. After electrification, the difference of soil settlement between cathode and anode is about $1 \mathrm{~mm}$.

\section{(4) Heavy Metal Variation Analysis}

There are many kinds of heavy metals in the soil. In this experiment, copper and zinc were used to study the change of heavy metal content in soil under the condition of combined electro-osmotic loading. See figure 3-5 and 3-6 below. 


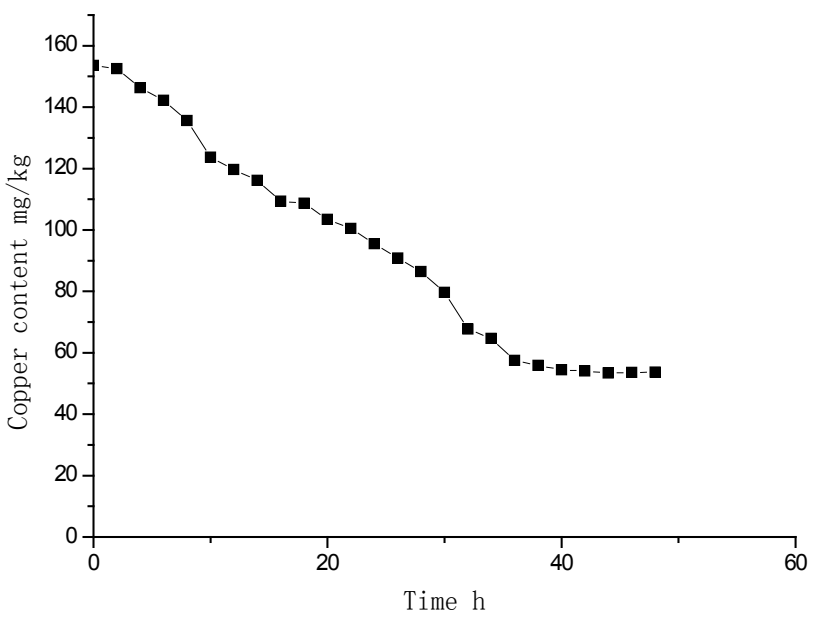

Figure 3-5. Copper content change diagram

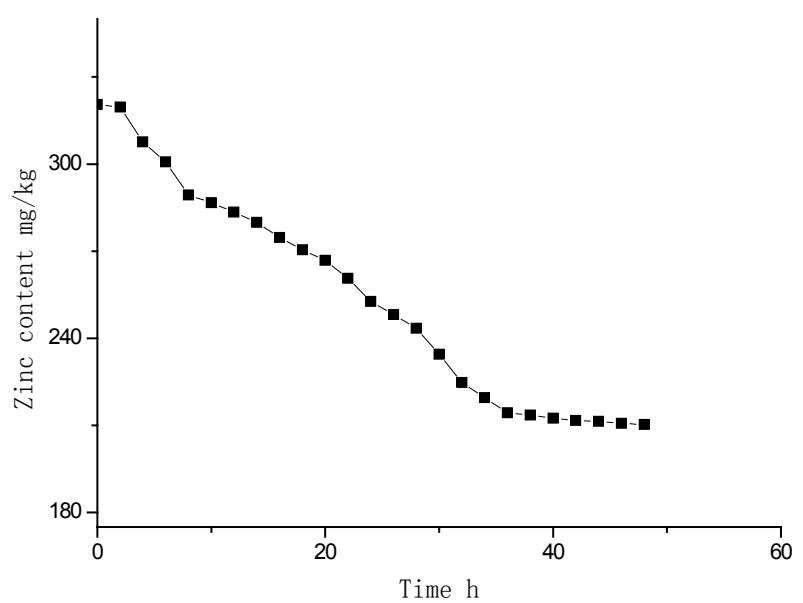

Figure 3-6. Change of zinc content

At the beginning of electro-osmosis, the copper content was $153.62 \mathrm{mg} / \mathrm{kg}$, the zinc content was 320.53 $\mathrm{mg} / \mathrm{kg}$, the content of copper was $53.68 \mathrm{mg} / \mathrm{kg}$ and the content of zinc was $210.27 \mathrm{mg} / \mathrm{kg}$ after completion of the experiment. According to the standard value of soil environmental quality in GB15618, the contents of $\mathrm{Cu}$ and $\mathrm{Zn}$ were basically in the second order (the content of the second grade copper was $<50$, the content of the second grade zinc was $<200)$ [7]. This method can alleviate the problem of urban soil tension.

\section{Conclusion}

(1)The total amount of drainage in 48 hours is $695.5 \mathrm{ml}$, the average drainage rate reached the maximum $25 \mathrm{ml} / \mathrm{h}$ and the maximum hourly displacement reached $65 \mathrm{ml} / \mathrm{h}$ in $1 \mathrm{~h} \sim 20 \mathrm{~h}$. After that, the drainage rate gradually slowed down. The combination of electro-osmotic method and pile-loading experiment has strong capacity of drainage consolidation.

(2)At the end of the experiment, the content of copper and zinc basically reached the second order standard, so electro-osmosis combined with pile-loading has certain effect on removing heavy metals. 
Acknowledgements. The work is supported by Post-graduate's Innovation Fund Project of Hebei University under grant no. X201720.

\section{References}

1. Chen Wen-ting. Study on treatment of heavy Metals in sludge of Municipal sewage treatment Plant by Electrodialysis. Chang'an University.

2. Zang Junchao, Zheng Lingwei, Xie Xinyu, Cao Liwen, Li Zhuoming. Experiment on electro-osmotic reinforcement of contaminated soil from domestic sources. Journal of Zhejiang University (Engineering Edition: 245-254).

3. Wang Jun, Zhang Le, Liu Feiyu, Fu Hongtao. Experimental study on consolidation of soft clay foundation by vacuum preloading and electro-osmotic method. Journal of Rock Mechanics and Engineering: 4181-41922.

4. Jiao Dan, Gong Xiaonan, Li Ying. Experimental study on strengthening soft soil by electro-osmotic method. Journal of Rock Mechanics and Engineering

5. Ren jubo. Experimental study on the new surcharge electro-osmotic method for strengthening the foundation of dredged silt.

6. Fu Hongtao, Wang Jun, Cai Yuanqiang, Zhang Le, Cai Ying. Experimental study on consolidation of soft clay foundation by low energy dynamic compaction and electro-osmotic method. Journal of Rock Mechanics and Engineering: 612-620.

7. GB 1568-2008 soil Environmental quality Standard. 